\title{
Assessing the impact of pasture resting on pasture condition in the extensive grazing lands of northern Australia
}

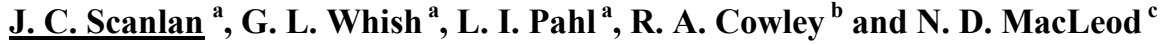 \\ ${ }^{a}$ Department of Employment Economic Development and Innovation, P.O. Box 102, Toowoomba, Qld. 4350 \\ ${ }^{b}$ Department of Resources' Darwin NT 0800 \\ ${ }^{\mathrm{c} C S I R O ~ E c o s y s t e m ~ S c i e n c e s, ~ D u t t o n ~ P a r k, ~ Q ~} 4102$. \\ Email:joe.scanlan@deedi.qld.gov.au
}

\begin{abstract}
Pasture resting (spelling) during the early wet season, has been identified as an ecologically useful tool for restoring degraded rangeland pastures. Resting has been included within a suite of promising grazing land management practices being evaluated within the Northern Grazing Systems program, coordinated by Meat and Livestock Australia. The GRASP pasture simulation model has been used to investigate many aspects of grazing land management, from estimating safe stocking rates through to assessing the impact of projected climate change. The investigation of pasture response to resting required some important modifications to the GRASP model.
\end{abstract}

Change in pasture condition as simulated by GRASP was previously based on annual utilisation rates of pasture growth. As such, the actual timing of grazing had no impact on change in condition and this is an appropriate means of calculating change in condition when paddocks are continuously grazed throughout the year. However, pasture resting means that grazing is undertaken for only part of the year. Tropical grasses are most sensitive to grazing during the early part of the growing season - December to March. If ungrazed during this period, pastures will generally improve in condition; if heavily grazed, pastures will deteriorate markedly. We describe changes made to the GRASP model to enable simulation of pasture resting regimes.

Three applications of the modified GRASP model are reported. The first deals with the pasture response to different frequencies and lengths of rest periods, with this information being averaged across 20 different climate windows (each 30 years) to overcome the possibility that a particular climatic period produced an 'unusual' response. The second covers the change in pasture condition for a recommended resting regime where animals are agisted off-property, and the third is a variant of the second application with the displaced animals being distributed across the other paddocks involved in the rotational resting regime.

Pasture resting resulted in marked improvement in both pasture condition and production. As the frequency and duration of rest periods increase, so does the condition and productivity of pastures. Importantly, frequent, shorter rests produced better responses than less frequent, longer rests. A rotational rest grazing system involving four paddocks, with each paddock receiving a 6-month rest on a one-in-four year cycle, improved pasture condition in the system as a whole, especially when the cattle from the rested paddocks were agisted off-property. When the system involved those stock from the rested paddock being distributed across the other three paddocks being grazed, one of those paddocks commonly showed deterioration in condition. This is due to the three consecutive years in which the last paddock in the cycle to receive a rest has a stocking rate which was 33\% higher than the long-term stocking rate during the sensitive summer growing period.

Limitations to the use of these modelling results are considered and practical changes to the simulation approach are discussed.

Keywords: Pasture rest, pasture condition, grazing management, extensive grazing systems 


\section{INTRODUCTION}

Some pasture deterioration has occurred within northern Australia with a major documentation of this provided by Tothill and Gillies (1992). Some of this deterioration has been associated with major degradation events (McKeon et al. 2004). Pasture resting has been identified as a possible means of improving pasture condition in these degraded lands and is part of the Grazing Land Management workshops run by state agencies with financial support from Meat and Livestock Australia (Chilcott et al. 2005).

The Northern Grazing Systems (NGS) project has been developed between Meat and Livestock Australia, CSIRO, and Queensland, Northern Territory and Western Australian agencies involved in grazing management activities. Pasture resting was identified as a research topic for bio-economic modelling within the NGS project. Major insights to date have recently been reported by McIvor et al. (2011).

A scoping project identified the GRASP model (McKeon et al. 2000, Rickert et al. 2000) as the most appropriate modelling tool to simulate the effects of pasture resting. This model has been used for a wide range of studies in the extensive grazing lands in Australia (Carter et al. 2000; McKeon et al. 2008). However the original model did not adequately represent some of the biological responses needed to evaluate the effects of pasture resting.

The aim of this work was to simulate the effect of resting on pasture condition and soil loss for a moderately fertile land type in north-eastern Queensland, and to simulate the effects of a pasture resting system where cattle from rested paddocks were either agisted off-property or grazed on other paddocks within the resting system.

\section{METHOD}

\subsection{Modifications to GRASP}

GRASP is a dynamic, pasture-animal growth model that has been widely applied to evaluate the effects of various grazing management practices in Australia, including stocking rate estimation (e.g. Johnston et al. 1996) and potential impacts of climate change (e.g. McKeon et al. 2008; Scanlan et al. this volume).

The original version of GRASP was unable to model the full impacts of pasture resting as the utilisation of growth was not sensitive to the season of that utilisation. As a result of this formulation, grazing during the summer growth period had the same impact as grazing during the winter period when the dominant pasture species are dormant. Mott et al. (1985) have shown that excessive grazing during the growing season decreases pasture condition, depending on the degree of utilisation of growth in the growing season. This necessitated modification of the model to account for the known biological response to grazing during the growing season.

The major modification involved weighting the impact of utilisation depending on the month in which that utilisation occurred (Figure 1a). At one extreme, the impact of grazing in each month is equal (as may be the case in aseasonal locations) and at the other extreme, $100 \%$ of the impact occurs during the summer growing season of northern Australia.

Utilisation is used to estimate the change in pasture condition state (Figure 1b). There are several critical parameters: the magnitude of change at $0 \%$ and $100 \%$ utilisation; the utilisation rate at which there is no change in condition (the safe utilisation rate where the line crosses the X-axis), and utilisation rate at which the rate of change increases from being low close to the safe utilisation to being more pronounced at high or low utilisation rates. This differs from the original GRASP model in which the change of state was 0 around the safe utilisation level and 1 (or a larger integer) above or below the thresholds.

In the original GRASP model, pasture condition state was represented as an integer value from 0 (excellent condition) and 11 (very poor condition) (Figure 1 in McKeon et al. 2000). In the revised model, state can be represented by any real value between 0 and 11 and the relationship between state and percentage perennial grasses is shown in Figure 1c. In an ungrazed pasture ( $0 \%$ utilisation) the state can decrease (i.e. improve) by a specified maximum (usually between 1.2 and 1.5); at 100\% utilisation the state can increase (i.e. degrade) by a specified maximum as shown in Figure 1b. State does not change when utilisation is at the specified safe level (30\% in Figure 1b). Percent perennial grass is used as the indicator of condition and varies between a maximum of $90 \%$ and a minimum of $1 \%$. While some land types may not have $90 \%$ perennial grass even when in excellent condition, in this representation of condition, pasture in its maximum possible condition will be represented as $90 \%$ perennial grass. 
(a)

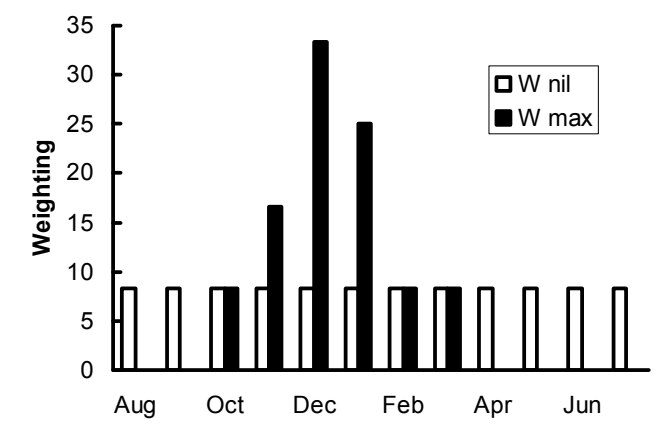

(c)

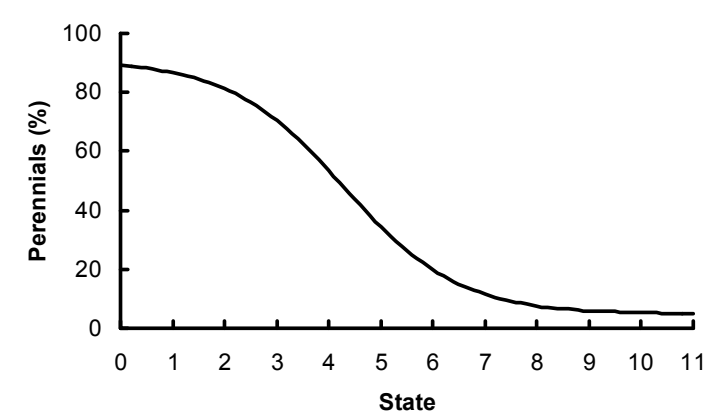

(b)

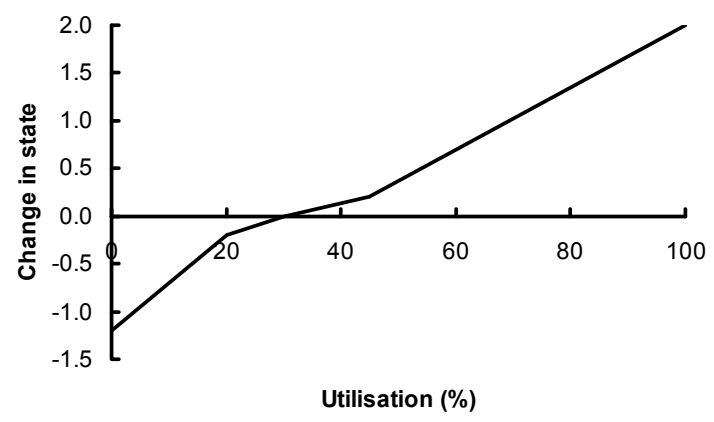

Figure 1. Elements in calculation of perennials (\%) within GRASP (a) monthly weighting applied to utilisation per month showing W Nil (nil weighting) where all months contribute $8 \%$, and W max (maximum weighting) where the six months shown contribute a total of $100 \%$ to utilisation calculation; (b) change in state as a function of utilisation (\%), and (c) perennials (\%) as a function of state.

\subsection{Single paddock resting}

When using fixed stocking rates with negative feedback of high utilisation on pasture productivity, poor production in one year can lead to a high utilisation of pasture growth which can lead to a drop in condition with lower pasture production in the following year. To avoid drawing conclusions that are specific to just one climatic window, we simulated the response to pasture resting using 20 different 30 -year windows when considering the impacts of different frequency and length of rest periods.

The resting frequencies simulated for the goldfields land type at Charters Towers in north Queensland (Whish 2011) were annual, 3 years out of 4 , every 2 years and once in 4 years. The lengths of rests were 2, 3 and 6 months from $1^{\text {st }}$ December. This approximates the start of the growing season. All combinations of frequencies and length of rest were simulated for each of the 20 climatic windows, each of 30 years.

Four fixed stocking rates were used in the simulations spanning the range from conservative (13 AE [adult equivalents] per 100 hectares) through to excessive stocking rates (23 AE per $100 \mathrm{ha}$ ).

\subsection{Four paddock resting system}

A four-paddock rest system was simulated with each paddock receiving a 6-month rest (starting on $1^{\text {st }}$ December) once every four years. All paddocks were the same size and started in poor condition - equivalent to $20 \%$ perennials. The simulation period was 28 years so that each paddock received 7 periods of rest during the simulation. Paddock 1 received a rest in the first year, then paddock 2 in the second year, paddock 3 in the third year and finally paddock 4 was rested in year 4 . The cycle then repeated. When considering the resting regimes, we used five climate windows.

The fixed stocking rate chosen was that which maintained the unrested paddock in more-or-less the same condition as it started (about 20\% perennials). Thus, the actual stocking rates chosen for each climatic window were different: for simulations starting in 1964, the rate was $12 \mathrm{AE} / 100$ ha; commencing 1968 it was $13 \mathrm{AE} / 100 \mathrm{ha}$; commencing 1972 it was $16 \mathrm{AE} / 100$ ha; commencing 1976 it was $15 \mathrm{AE} / 100$ ha; and commencing 1980 it was $14 \mathrm{AE} / 100$ ha. 
In the first simulations, the cattle from the rested paddocks were moved out of the 4-paddock system. The stocking rate in all paddocks was the same during the periods in which they were grazed. In the second set of simulations, the cattle from the paddock rested for the 6-month period were evenly distributed across the remaining three paddocks.

\section{RESULTS}

\subsection{Single paddock impacts}

The longer the pasture rest (at a frequency of once every 4 years), the better was the pasture response in terms of growth, percent perennials and soil loss (Table 1). At the highest stocking rate (21 AE/100 ha), recovery did not occur when a single rest every four years was provided, no matter how long that rest was. The more frequent the rest (for a 3-month rest period), the better was the pasture response in terms of improved pasture condition, increased pasture growth and reduced soil loss (Table 2). A 3-month rest every year led to almost complete recovery (mean of $71 \%$ perennials) in the high stocking rate (21 AE/100 ha). Two simulations provided the same total rest period - a 3-month rest every 2 years (Table 2), and a 6-month rest every 4 years (Table 1). The double rest led to a greater improvement in pasture condition for the higher stocking rates $(55 \%$ cf $40 \%$ for $17 \mathrm{AE} / 100$ ha; $25 \%$ cf $12 \%$ for $21 \mathrm{AE} / 100$ ha). Comparable differences for growth and soil loss are evident.

Table 1. Effects of stocking rate (SR) and length of resting (one year in four) for a goldfields land type in north Queensland on perennials (\%), pasture growth and total annual soil loss - means of 20 simulations each 30 years.

\begin{tabular}{|c|c|c|c|c|}
\hline SR (AE/100 ha) & No rest & 2 months $1 / 4$ & 3 months $1 / 4$ & 6 months $1 / 4$ \\
\hline & \multicolumn{4}{|c|}{ Perennials (\%) } \\
\hline 13 & 42 & 58 & 64 & 72 \\
\hline 17 & 4 & 23 & 36 & 40 \\
\hline \multirow[t]{2}{*}{21} & 3 & 4 & 5 & 12 \\
\hline & \multicolumn{4}{|c|}{ Growth (kg/ha/year) } \\
\hline 13 & 2652 & 3172 & 3368 & 3611 \\
\hline 17 & 1426 & 2034 & 2441 & 2581 \\
\hline \multirow[t]{2}{*}{21} & 1254 & 1347 & 1412 & 1654 \\
\hline & \multicolumn{4}{|c|}{ Soil loss (kg/ha/year) } \\
\hline 13 & 1344 & 791 & 587 & 350 \\
\hline 17 & 2755 & 2003 & 1586 & 1389 \\
\hline 21 & 3335 & 3039 & 2877 & 2521 \\
\hline
\end{tabular}

Table 2. Effects of stocking rate (SR) and frequency of a 3-month rest for a goldfields land type in north Queensland on perennials (\%), pasture growth and total annual soil loss - mean of 20 simulations each 30 years.

\begin{tabular}{|c|c|c|c|c|c|}
\hline SR (AE/100 ha) & No rest & 3 months $1 / 4$ & 3 months $2 / 4$ & 3 months $3 / 4$ & 3 months $4 / 4$ \\
\hline & \multicolumn{5}{|c|}{ Perennials (\%) } \\
\hline 13 & 42 & 64 & 77 & 83 & 84 \\
\hline 17 & 4 & 36 & 55 & 73 & 80 \\
\hline \multirow[t]{2}{*}{21} & 3 & 5 & 25 & 55 & 71 \\
\hline & \multicolumn{5}{|c|}{ Pasture growth $(\mathrm{kg} / \mathrm{ha} /$ year $)$} \\
\hline 13 & 2652 & 3368 & 3763 & 3935 & 3975 \\
\hline 17 & 1426 & 2441 & 3077 & 3619 & 3864 \\
\hline \multirow[t]{2}{*}{21} & 1254 & 1412 & 2090 & 3086 & 3570 \\
\hline & \multicolumn{5}{|c|}{ Soil loss (kg/ha/year) } \\
\hline 13 & 1344 & 587 & 237 & 133 & 110 \\
\hline 17 & 2755 & 1586 & 901 & 358 & 189 \\
\hline 21 & 3335 & 2877 & 1942 & 894 & 389 \\
\hline
\end{tabular}

\subsection{Four paddock resting system}

When resting was undertaken during different climatic windows, the mean effect of resting was to improve the percentage of perennials in the pasture for the rested paddocks, while there was no long-term recovery in the paddocks that were not rested. The results from two different climatic windows are presented in Figure 1, showing the least (1964-1982) and the greatest change in the paddocks not rested (1976-2004); similar responses were seen in the other simulation periods (data not shown). 
(a)

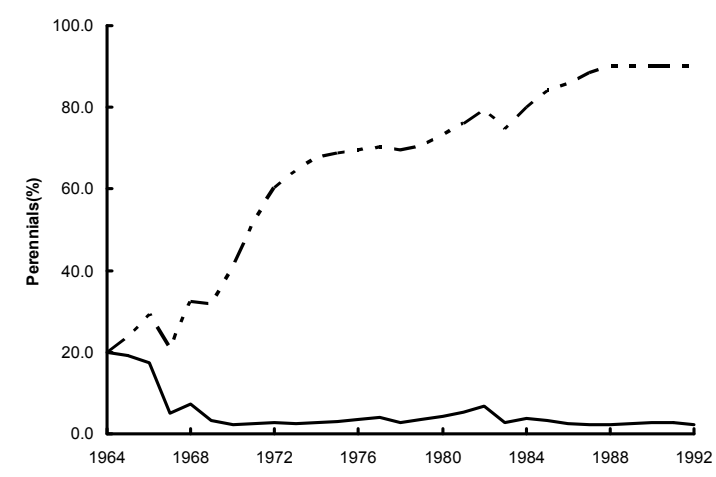

(b)

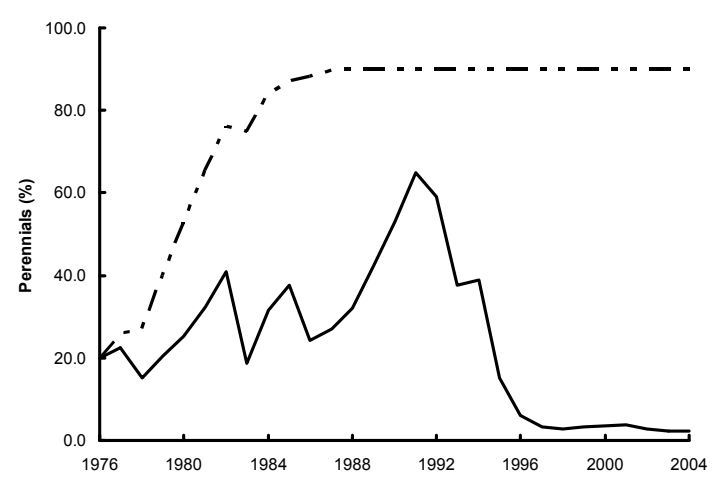

Figure 2. Influence of climate window on rate of recovery in perennials (\%) for a goldfields land type in north Queensland with cattle from rested paddocks being agisted. (Solid line is unrested; dashed line is for paddocks for six months every four years)

(a)

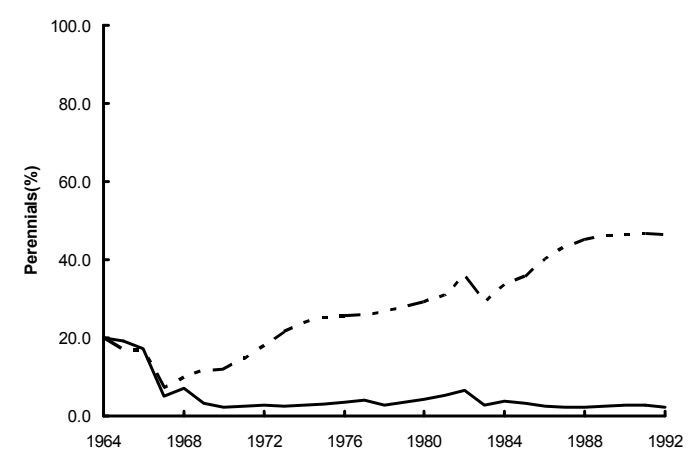

(b)

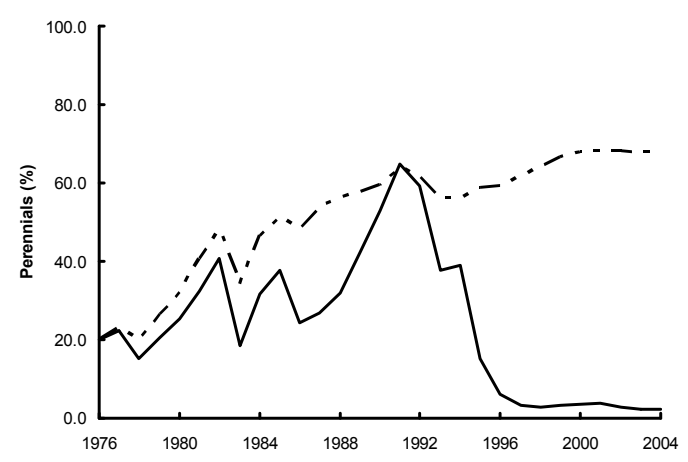

Figure 3. Influence of climate window on rate of recovery in perennials (\%) for a goldfields land type in north Queensland with cattle from rested paddocks placed into remaining paddocks. (Solid line is unrested; dashed line is mean of four rested paddocks)

The mean rate of improvement for the paddocks receiving a 6-month rest every 4 years was much slower when the cattle from the paddock being rested were grazed on the other three paddocks in the system (compare same time periods in Figure 3 versus Figure 2). In particular, note that the mean percent perennials for rested paddocks commencing in 1976 till 1991 were quite similar to the paddock not being rested and that the percent perennials did not improve much after that, remaining around $60-70 \%$. For the same period in Figure 2, the percent perennials increased rapidly from 1978-1986, and then remained close to the maximum $90 \%$ for the rest of the simulation.

The period from 1976 to 2004 was examined in more detail as seen in Figure 4. Here, the percent perennials in each of the paddocks is shown separately. Paddocks 1 and 2 received their rest period in the first and second years, respectively. Paddock 4 did not receive a rest till the fourth year. In this paddock, the percent perennials remained low during the simulation period and was always lower than the paddock that did not receive a rest (refer to Figure 2). 


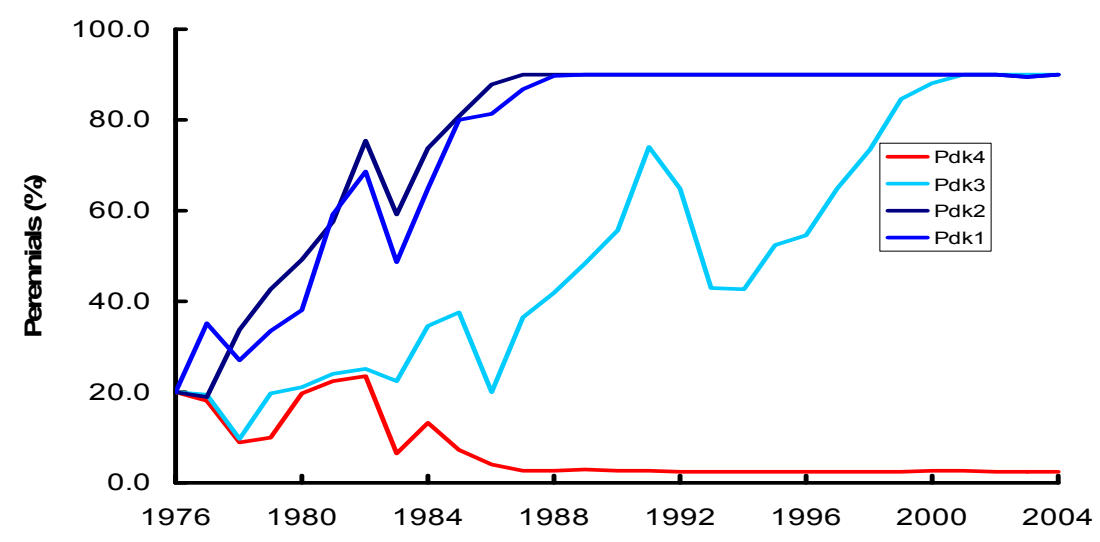

Figure 4. Differences between perennials (\%) in a 4-paddock system in which the cattle from rested paddock are loaded into remaining paddocks.

\section{DISCUSSION}

At the individual paddock level, pasture resting resulted in marked improvement in pasture condition, improved pasture production and reduced soil loss. The more frequent are the rest periods and the longer those rest periods are, the larger and more rapid are those responses. The model results suggest that more frequent shorter rests will produce better responses than less frequent longer rests. At least in part this is a result of the formulation of the model in that the adverse impacts of grazing is most pronounced during the early-mid part of the growing season (Figure 1a).

Another consequence of the formulation of the model is that the potential benefits of pasture resting will be smallest in those locations where growth is aseasonal and will potentially be greatest where growth is most strongly seasonal. These extremes are represented in Figure 1a. Further investigation is required to determine if there are consistent differences between land types both within and between regions.

The response to resting is very sensitive to the selection of stocking rate. If the stocking rate exceeds the safe carrying capacity of a particular land type in a particular condition, then resting will have few long term beneficial effects. At the other extreme, if stocking rates are lower than the safe carrying capacity, pasture condition will improve, even in the absence of pasture resting. In these situations, resting will lead to a more rapid improvement; hence it would have some benefits.

When considering resting as part of a planned system within a property, a number of issues need to be addressed. Most important of these is the question of what happens to the cattle from the paddock receiving the rest. Options range from being moved off-property to agistment, moved onto ungrazed areas of the property or into other grazed paddocks on the same property ("loading up" the other paddocks). From a modelling perspective, the first two options are the same, while the last one is fundamentally different.

In a four-paddock resting system with loading up, the three grazed paddocks each receive an increase in stocking rate of $33 \%$ during the rest period of the other paddock. This will lead to a greater impact of grazing during that period (which is usually the summer growing period). In the case of the last paddock to receive a rest, there has been a sequence of three years in which it has experienced a higher stocking rate during the summer growth period during which most tropical grasses are sensitive to grazing (referred to as the " 4 th paddock problem"). When this situation is modelled using a fixed stock number over the whole four paddocks, this paddock declines in condition and ends in a poorer condition compared with the unrested control paddock. This assumes that the stocking rate used was not low (compared with the safe stocking rate), in which case all paddocks could improve in condition as outlined above.

There are substantial differences between what has been done in this modelling work and what could or would be implemented on a grazing property. Fixed stocking rates are unlikely to be used rigidly, and small year-to-year variation in stock number may influence the outcome. Resting is unlikely to be implemented during poor seasonal conditions, especially in light of the potential problems associated with the $4^{\text {th }}$ paddock problem. In this modelling work, the resting was implemented on a fixed timing - starting on $1^{\text {st }}$ December and ending on $31^{\text {st }}$ May in the following year. Again, in a typical property situation, this rigid approach would probably not be followed, with the graziers responding to within-season conditions for commencing and/or ending the rest period. 
A number of options are being investigated to avoid the $4^{\text {th }}$ paddock problem. One obvious option is to allocate the stock from the rested paddock to the other paddocks in proportion to their capacity to carry those extra animals without causing excessive damage in one paddock compared to another. Within the current GRASP model, this is not possible to simulate. A key option is to agist stock during the first cycle of the simulation. This may allow all paddocks to improve sufficiently in that first cycle and prevent the $4^{\text {th }}$ paddock problem from arising. To make the comparison with the unrested paddock more appropriate, the stocking rate in the unrested paddock should be reduced by $1 / 8^{\text {th }}$ (being equivalent to one 6 -month rest per year in the four paddocks). Some preliminary modelling suggests that this may lead to an improvement in the control paddock as well.

\section{ACKNOWLEDGMENTS}

The authors acknowledge Drs Rodd Dyer, Mick Quirk and Wayne Hall for their guidance throughout this continuing work and Meat and Livestock Australia for their development and funding of the Northern Grazing System project. Additional funds were received through the Australian Department of Agriculture, Fisheries and Forestry's Caring for Our Country and Australia's Farming Future: Climate Change Research programs. Dr Greg McKeon has provided insights and encouragement during this work.

\section{REFERENCES}

Carter, J. O., W.B. Hall, K.D. Brook, G.M. McKeon, K.A. Day, and C.J. Paull. (2000). AussieGRASS: Australian Grassland and Rangeland Assessment by Spatial Simulation. In: 'Applications of Seasonal Climate Forecasting in Agricultural and Natural Ecosystems - the Australian Experience'. (Eds G. Hammer, N. Nicholls and C. Mitchell.) pp. 329-349. (Kluwer Academic Press: Dordrecht, The Netherlands.)

Chilcott, C.R., B.S. Nelson, M.F. Quirk, and C.J. Paton. (2005). Grazing Land Management - Burdekin Version. (Meat and Livestock Australia, Sydney).

Johnston, P. W., G.M. McKeon, and K.A. Day. (1996). Objective 'safe' grazing capacities for south-west Queensland Australia: development of a model for individual properties. The Rangeland Journal 18, 244258. doi: 10.1071/RJ9960244

McIvor, J.G., S.G. Bray, A.C. Grice, L.P. Hunt, and J.C. Scanlan. (2011) Grazing management options for improving profitability and sustainability 1. New insights from experiments. Northern Australia Beef Research Update Conference, Darwin, August 2011.

McKeon, G.M., A.J. Ash, W.B. Hall, and M. Stafford-Smith. (2000) Simulation of grazing strategies for beef production in north-east Queensland. In Applications of seasonal climate forecasting in agricultural and natural systems-The Australian experience. (Eds. G. Hammer, N. Nichols and C Mitchell.) pp. 227-52. Kluwer Academic Press, Netherlands.

McKeon, G. M., W.B. Hall, B.K. Henry, G.S. Stone, and I.W. Watson. (2004). 'Pasture Degradation and Recovery in Australia's Rangelands: Learning from History.' (Queensland Department of Natural Resources, Mines and Energy: Brisbane.)

McKeon, G.M., Stone, G. S, Syktus, J. I., Carter, J. O., Flood, N. R., Ahrens, D. G., Bruget, D. N., Chilcott, C. R., Cobon, D. H., Cowley, R. A., Crimp, S. J., Fraser, G. W., Howden, S. M., Johnston, P. W., Ryan, J. G., Stokes, C. J. and Day, K. A. (2009). Climate change impacts on northern Australian rangeland livestock carrying capacity: a review of issues. Rangeland Journal. 31: 1-29

Mott, J.J., J. Williams, M.H. Andrew, and A.N. Gillison. (1985). Australian savanna ecosystems. In "Ecology and Management of the World's Savannas" (ed. J.C. Tothill and J.J. Mott), pp. 56-82. Australian Academy of Science, Canberra.

Rickert, K.G., J.W. Stuth, and G.M. McKeon. (2000). Modelling pasture and animal production. In: Field and Laboratory Methods for grassland and Animal Production Research (eds. L. 't Mannetje and R.M. Jones). (CAB International Publishing: New York).

Scanlan, J.C., R.C. Cowley, L.I. Pahl, G.L. Whish, and N.D. MacLeod. (2011) Potential impacts of projected climate change on safe carrying capacities for extensive grazing lands of northern Australia. MODSIM 2011.

Tothill, J. C., and C. Gillies. (1992). The pasture lands of northern Australia: their condition, productivity and sustainability. Occasional Publication No. 5. Tropical Grasslands Society of Australia: Brisbane.

Whish, G.L. (2011). Land types of Queensland. Version 2.0. Prepared by the Grazing Land Management Workshop Team, PR07-3212, Department of Employment, Economic Development and Innovation, Brisbane. 